\title{
Culture and Emotional Intelligence: How Much Does Culture Influence Emotional Intelligence Among Ghanaians?
}

\author{
*Alfred Dickson Dai-Kosi ${ }^{1} \quad$ Victoria Akuorkor Acquaye ${ }^{2}$ \\ 1.Department of Community and Preventive Dentistry, School of Medicine and Dentistry, University of Ghana, \\ Legon. Ghana \\ 2.Department of Psychological Medicine and Mental Health, University of Cape Coast, Ghana
}

\begin{abstract}
Emotional intelligence plays an important role in determining how each individual interprets and acts on his or her feelings in relation to himself and to other important people he or she comes into contact with. There are many factors that influence how an individual develops this ability of identifying or using the emotional intelligence including culture. This paper sought to assess the level of influence of culture on emotional intelligence and also whether it has affected Ghanaians negatively or positively. It was revealed from literature review that culture influences emotional intelligence and that Ghanaian culture has largely many positive methods that can be used to train children in developing sound emotional intelligence.
\end{abstract}

Keywords: key words, Emotional intelligence, culture, psychological, social skills, personality

DOI: $10.7176 /$ RHSS/10-14-03

Publication date:July $31^{\text {st }} 2020$

\section{Introduction}

The demands of the $21^{\text {st }}$ century make it imperative that citizens especially students of every progressive country are emotionally intelligent and flexible in the use of knowledge gained to develop transferable skills especially in literacy, numeracy, practical solution and self-management. In many instances, people who are able to utilize the benefits of emotional intelligence develop many skills some of which include identifying and managing their own emotions and that of others in any domain of life (Chechi, 2012). Chechi, (2012) further noted that people whose emotional skills are well developed, benefit in more productive ways by effectively managing their lives, mastering the habits that lead to independence of thought with strong self-drive. Seligman, (2002) indicates that emotional intelligence enhances healthy mental well-being and can lead to development of individual skills including leadership and entrepreneurial abilities. However, a section of Ghanaians have expressed the views that it seems taking initiative especially in engaging in activities that enhance individual potential has become a difficult task for many Ghanaians especially the young ones. The fact that many of the youth seem not to display a strong drive for initiative has been identified to be one of the reasons why many youth in Ghana looks up to the government and the private sector for employment without making effort to become self-employed (Leung, 2005). One of the key factors that influences an individual's ability to recognize and endeavour to develop his or her potential is emotional intelligence. Emotional intelligence which shapes each person's recognition of feelings, strengths and weaknesses can be imparted in many ways by culture. How much have cultural and traditional beliefs and standards moderated the perception of the Ghanaian in recognizing, tapping and developing their talents and other traits is the key concern of this paper., extra queuing time, lost business income, etc. In order to prevent these deteriorative effects, optimising the number of workers can be helpful. As a fundamental branch of knowledge in manufacturing business, workforce management will never fall behind the times. Therefore, it is worth an attempt to incorporate a novel methodology, such as HMS, into the state of the art of workforce sizing.

\section{Emotional intelligence}

Emotional intelligence is the ability both to know one's own emotions and also identify that of other people (Zandel, 2008). Emotional intelligence has three key models namely: The ability model, developed by Peter Salovey and John Mayer (Mayer, Salovey, \& Caruso, 2004), which focuses on the individual's ability to process emotional information and use it to navigate the social environment. The second, the trait model was developed by Petrides and Furnham, (2001). This covers behavioral dispositions of the individual and personal perception of his or her abilities. The third and final, the mixed model is a combination of both ability and trait models in measuring emotional intelligence. Gardner and Qualter (2010) pointed out that people with high emotional intelligence have greater mental health, exemplary job performance and more potent leadership skills.

The concept of emotional intelligence became much more popular following the immense success of Daniel Goleman's book in 1995: Emotional intelligence, "Why it Matters more than IQ". He explored the important linkage between IQ and emotional intelligence and how the interconnectivity can help address challenges in every domain of life. Emotional intelligence was explained as having that unpredictable power and strength and may take you unaware but you need to be able to recognize it and tap into it for optimum benefits (Madhar, 2010). Emotional Intelligence focuses on four areas of capacities or skills including the ability to: i) understand ii) manage 
iii) perceive and iv), use emotions to facilitate thoughts (Mayer, Salovey, Caruso \& Sitarenios, 2003). Indeed emotional intelligence helps in controlling people's emotions, in terms of thoughts and conducts which readily gives the individual the best of life and excellent personality qualities (Damasio, 1994; Le Doux, 1996). Damasio (1994) also explained that the issue of emotional intelligence is an interplay between emotions and cognitions to the outmost benefit to the individual and society.

Emotional intelligence has been applied in many aspects of human endeavour. Some of the key areas of its application include school performance, classroom management, discipline, productivity at work places, motivation, self-drive and innovation. It has attained high levels of importance virtually in all fields dealing with people (Chechi, 2012). Socio-cultural influences may also play important roles in influencing emotional intelligence of individuals.

There are several definitions of culture, but for the purpose of this paper the following are adopted: Baxter (1998) describes culture as what attributes meanings to one's life. Baxter indicated that culture provides social roles for its members, determining how members of a particular culture express their feelings, emotions and distress and experience conflict in behaviour, thought or action. Culture in this sense, is the shared resource of language and actions such as body language and all physical activities, ethics and history. Again culture is described as lifestyle as manifested by a particular people or society. Culture can therefore be referred to as manmade, not including genetically inherited. Culture evolves and grows and imbibed by the people. Culture thus evolved for the purpose of living (Ross, 1998). Ross also explained that culture is expressed in intangible or nontangible form, typically in terms of language, dialects, and philosophical thoughts. Others include cosmology, morals and ethics, religious beliefs and rituals, oral traditions, folklore, festivals, political ideas, music and dance, social customs related to birth, puberty, marriage, family life, work, death and others. In terms of tangible or material manifestation, it includes: types of food procurement and preparation, diverse technology and crafts, clothing, body adornment, art work and symbols, secular and religious architecture, monetary medium of exchange, and transportation system.

Idang (2015) confirms these elements of culture in relation to Africans notably language, food, marriage life, customs and traditions. He reveals that there are many standards set by cultural boundaries to guide the way of life of different cultural groups. Indeed since these cultural norms have become the embodiment of the people, norms to a large extent influence how a group of people behave and display emotions and other psychological traits that can affect their lives. According to Gyekye (2003) Africans have a very strong cultural root which virtually permeates all facets of their lives. It is therefore very important to assess the influence of these cultural practices and standards in the recognition, and development of emotional intelligence among Ghanaians. This is very essential since the development of strong emotional intelligence and how to interpret them in a positive way very much signals the direction of growth and development of a people. Wiredu (1996) stressed the importance of communication as means of giving meanings and signals. In that regards the ability to recognize these signals within an individual or in others is crucial for quick interpersonal relations. The recognition of these communication linkages can best be enhanced with a sound emotional intelligence.

\subsection{Cultural Beliefs}

African and for that matter Ghanaian life is traditionally communal and that they hold in high importance certain social values such as social solidarity, harmony and cooperation (Idang, 2015). According to Idang (2015), Africans often go along with the greater group and try to conform to that communal or collective goal of their respective societies in order to avoid curses or misfortunes. That is once you are a member of a community, you grow and mature, participating more actively in the ceremonial rites and festivals of the community which include singing, drumming and dancing. Umoh (2005) points out that African communal life is also bound together with religion which is not primarily for the individual, but for the entire community. He further explained that to be born into a human community is to be born into a religious community and that one needs to abide by the tenets of the society. Gyekye (2003) emphasizes that although Ghanaians and for that matter Africans are highly communal, there is also room for individualistic living and that individuals are allowed to grow and develop their talents. An assertion which Appiah (1992) strongly supported when he advised that any attempts to limit the identity of an individual to one set of factors such as race, gender, religion and above all culture is to create ways in which that person's identity is eventually restricted. In this regard, as Ghanaians have demonstrated such a strong communal bond or ties and are generally expected to act in the collective interest of society, how do they exhibit their individual identity through the expression of their emotional intelligence? The emotional intelligence becomes much more beneficial to the individual and society only if it is identified, and managed.

Literature shows that emotional intelligence affects many aspects of individual's life and that those who have sound knowledge and training as regards identifying their emotional intelligence have had massive impact in their endeavours as illustrated briefly below. A number of researchers conducted cross cultural studies to assess the relationship between culture and emotional intelligence and impact on type of quality of leadership. The results from different cultures including US and the UK by Jassawalla, Trugilia and Garvey (2004) and Malaysia by 
Shipper, Kincaid, Rotondo and Hoffman (2003) indicated positive relationships between manager effectiveness and the self-awareness component of emotional intelligence and that leaders quality correlated positively among the managers and leaders. This finding of the significant impact of emotional intelligence on quality of leadership was challenged by Leung (2005) who found that the espoused competencies of emotional intelligence among Western managers may clash with Chinese culture and values. In relation to the findings of the study, Illangovan, Scroggins, and Rozell (2007) proposed that Indian employees will prefer a more directive, task-oriented style of leadership, compared to the participative style advocated by many U.S. managers. These interesting findings and propositions clearly show that much as emotional intelligence influences quality of leadership, the extent of impact might differ significantly from culture to culture and calls for the need to assess this in different cultures with its unique attributes and values.

Another study concerning the impact of culture on employee performance was carried out by Zadel (2008) in which he explored the intersection of emotional intelligence and employee satisfaction from cultural perspective among Eastern European employees, while Illangovan et al (2007) also compared emotional intelligence and competencies among Indian and U.S. employees. The results revealed that just as that of the leaders, culture played significant role in the performance and competence of the employees.

An interesting study on emotional intelligence among Ghanaian footballers living in the United Kingdom was carried out by Caren and Diehl (2006). Results suggested that emotional intelligence correlated with performance; those who had strong emotional intelligence performed better. The results also showed that emotional intelligence was related to mood states associated with optimal and dysfunctional performance. It further indicated that emotion regulation and appraisal of other people's emotions contributed significantly to variations in mood by performance. When seen collectively, results demonstrated that there were cultural differences between the two populations from different cultural backgrounds which indicated that in both populations, Emotional intelligence could be enhanced for some of the participants. Culture could be an explanation for the intervention only partially working. The Emotional intelligence theory or the emotional intelligence may only work in the culture it was developed in as it did not seem to detect changes in the Ghanaian sample. It is in this regard that a number of researchers pointed out that culture plays and important role in the determination of a person's emotional intelligence. Since culture shapes the character development of an individual, it would suffice to explore its relationship with emotional intelligence in the classroom.

\subsection{Development of Emotional intelligence in the classroom}

According to Goleman (1998), emotional intelligence covers the following areas in each individual namely: 1) knowing one's feelings and using them to make good decisions in life. 2) being able to manage moods and control impulses and 3) being motivated and effectively overcoming setbacks in working towards goals. Every effective educational system is structured to bring out graduates who can compete globally and make positive change in society. This will make students think independently, be innovative and ready to solve problems thus leading to self-efficacy. Mac Mullin (1994) observed that students' social and emotional difficulties and their inability to use socially skillful ways to gain teacher's support can result in low academic achievement. This observation seems to be widespread in many schools in Ghana where students find it difficult to express their emotional intelligence to their teachers and therefore the teachers are not able to effectively address students' challenges individually. What could account for this? Perhaps the class sizes or societal upbringing. A case that needs further research in future. What then should be done by the teachers to unearth these talents and potentials among students? Goleman (1995), provides some strategies that can be categorized into three mainly: 1) Minimizing disruptive behaviour by as much as possible reducing confrontation in the classroom situation, 2) maximizing on-task behaviour, 3) helping students develop social skills. The philosophy behind these strategies is that effective learning needs high level of trust between students and teachers. This enables students feel at home and comfortable to associate closely with the teacher which can best be done in a supportive, friendly and interactive way both in and out of the classroom (O’Neil, 1996). The strategies are briefly explained below:

\subsection{Developing and Encouraging Non-confrontational Style}

Goleman (1995) noted that using a quiet and calm, gentle voice and avoiding finger stabbing and prolonged eye contact between a teacher and a student in general classroom interaction creates a non-threatening learning environment. The second key aspect of the non-confrontational strategy is the use of low-level interventions and walking around the classroom to ensure close proximity with students. Such close contacts effectively re-direct students to focus on task and help teacher corrects any form of undesired behaviour among the students. In this approach, the teacher provides a congenial atmosphere to develop privacy and respect for individuals and healthy learning environment. The third non-confrontational approach according to Goleman (1998), is the use of humour and distraction as appropriate. The aim of this technique is to reduce tension in the classroom and helps students recognize the need to match their conducts to situations. The skills of empathy and appropriate social skills are imparted using such method in the classroom 
3.2 Maximizing on-task behaviour and helping students develop social skills.

The second strategy which is maximizing on-task behaviour is also very crucial for the development of sound emotional intelligence among students (Goleman, 1995). Goleman, (1995) indicated that there is a high correlation between on-task behaviour and learning. He noted that students often engage in off-task behaviour because they are not clear about learning objectives or unable to maintain their motivation or assess their need for and effectively seek help. The development of intrapersonal intelligence helps students take responsibility for their learning and consequently maximizes on-task behaviour in the classroom. Goleman (1998), clearly outlined a number of measures to improving on-task behaviour among students. These include helping or assisting students to outline their task in terms of specific, short term goals situated in the overall objectives of learning which may include social and academic goals. Secondly identifying with each student, examples of his or her work which meet the standard and serves as guide for the students and their teachers. The process gets the students involved in the selfevaluation process which helps their intrapersonal skills.

The next important step in developing emotional intelligence in students is by helping them assess their personal needs in terms of equipment and external help. Both the teacher and the learner agree on ways of meeting such needs, support the process by asking non-threatening questions: 'Need for help?' 'Any problem?" This process leads students to develop the social skill for asking for help in a positive manner. Through these steps, students are assisted to develop their awareness of their own performance in relation to their objectives, and expectations for example, inspecting work in progress and asking: 'How are you getting on? or 'What should you do next?

And finally, reviewing task among students jointly with each individual students helps build up awareness of their achievement and strategies for building their strengths and overcoming problems.

\subsection{Developing Social skills in a cooperative environment}

Peer relationship can be viewed as the primary context for social and environmental growth on the individual because it is within these concepts of cooperation, mutual respect and interpersonal sensitivity, and experience companionship (Jordan, 1996). According to Jordan (1996), there are some students who are often labeled as difficult and intimidating. Hence the essence of inculcating emotional intelligence in them is to make them achieve safe and effective learning environment. This is done by involving all other students since it is only through such process that they can develop interpersonal skills. Jordan (1996), also noted that developing such skills in the students can be achieved through the following: 1) In the first instance, it can be achieved by involving students in setting social as well as academic expectations and targets for individuals and group activities. 2) The second important step is to create awareness among students about how their behaviour is perceived and also affects others. 3) Thirdly by helping students develop empathy and ability to negotiate and resolve conflicts and promote their own learning. 4) Also by monitoring each student's behaviour in terms of relations to others and achievement of their own objectives as individual and as a group. A teacher's ability to deal with problems and challenges firmly but with empathy provides a sense of assurance to vulnerable students whilst serves as a model of acceptable, assertive interaction for the whole class.

\subsection{Emotional intelligence and social skills development from Ghanaian perspective}

In developing the skills for identifying and developing emotional intelligence cultural variations play significant role (Leung, 2005). This assertion stresses the fact that the cultural background of each person can affect how he or she expresses or responds to emotions. Another important aspect is how such recognition of emotional intelligence helps in shaping character traits in individuals. Gyekye (2003) states that even though Ghanaians are predominantly collectivistic or communal, and that each member of the community is bound to abide by its tenets there is also provision for individuals to express their personal traits, responsibilities and emotions. For instance a member of the society is given individual identity and respect for his or her right. This is seen in the Akan maxim: All human beings are children of God; no one is a child of the earth. Gyekye (2003) explains that no human being is a child of the earth is a manifestation and insistence that we all belong to God and all must treat each other as such. There is another important Akan maxim which translates: life is as you yourself make it. The initial understanding of the maxim bears resemblance to the philosophical principle of existentialism by Jean Paul Sartre that man is nothing else but what he makes of himself. The linkage between the Akan maxim and the philosophical thought is that indeed the individual is responsible for himself or herself. This maxim together with another: the lizard does not eat pepper for the frog to sweat is cultural orientation that you will be held responsible for your acts.

On the other hand there are some important maxims that denote communal nature of the people. Notable ones are a person is not a palm tree that he should be self-complete or self-sufficient, one finger cannot lift up a load, if one person alone scrapes the bark of a tree for use as medicine, the pieces fall to the ground and the left arm washes the right arm and the right arm washes the left. All the above maxims are demonstration of how each individual 
needs the good of the general community to survive and progress in life. It also shows the need to be each other's keeper and thus instilling the social skill of unity, cooperation and empathy. These attributes are very similar to what Jordan (1996) proposed as the very essential traits and attributes that are taught in the classroom. Other essential maxims from different ethnic groups especially Ewe teaches on morality and against social vices as demonstrated in some Ewe proverbs for instance: 'It is because of shame that the harlot does not use the main street of the village'. Harlotry is one of the social evils in the traditional society and its practice produces a sense of guilt which is regarded as a punishment to those who indulge in it. The key moral teaching: Evil behaviour has its own punishment and therefore it does not pay in the long run to misbehave and serves as a caution against evil deeds and encourages good conducts.

Another important one on morality is: 'The person who steals mushrooms hears the evening announcement'. Meaning that in a village people who have found their crops or any personal belongings stolen cause an announcement to be made in the evening about the stolen crops or articles. In the announcement they ask the thieves to return the stolen goods or else they will be handed over to the gods for punishment. Usually they mention the name of a powerful god who is believed to invariably kill all evildoers. Thieves therefore listen carefully to the evening announcement and they also dread it. It may happen that someone has stolen some crops and his guilty conscience will cause him to behave as if he had heard an announcement about the crops he has stolen, even though there is no announcement. In other words, his conscience will be accusing him of his wrong deed. Moral Teaching: Guilty conscience is a form of punishment for wrong doing which any normal wrong-doer cannot escape and so it is better to put up good conducts.

There are also very some effective proverb on resilience and hard work some of the dynamic ones include: 'The person who has gone into a patch of giant-grass does not complain of skin irritation. This proverb comes from a farming experience and especially from farmers who work on the grassland. Sometimes they have to walk through the giant-grass to go to their farms and this produces a lot of skin irritation. Moral Teaching: The skin irritation caused by the giant-grass may be compared to minor distractions in the pursuance of one's objectives. The moral lesson of this proverb and of similar ones that will follow is that you must expect minor distractions in any effort that you put forth to realize certain objectives but do not let these minor distractions deter you from achieving your goals. You should not vacillate but be resolute and persistent in the pursuance of your goals. In this regards, students can be assigned challenging tasks and guided to accomplish them. The excitement that comes with such accomplishment cannot be compared to the effort in achieving the task.

The need to do due diligence in whatever transaction is highlighted in the following proverb which teaches us about identifying the ability of someone who claims to have a cure for your ailment. The proverb states: 'The vulture cannot cure baldness, (because if it can it would have cured its own baldness.). Moral Teaching: In the traditional society some people lay claim to certain powers to cure diseases, to make others wealthy or to cure barrenness among women. The problem is, how do you test the validity of the claims that they make? This proverb establishes a standard for evaluating such claims. Whatever powers a person claims to have, such powers must be seen to make a practical difference to his own life before his claims could be accepted as valid. If such consideration is not made anybody who accepts such claims without authenticating their efficacy will be considered gullible. The proverb is counselling against the tendency to be gullible in such matters and recommends critical assessment and discernment instead of gullibility. There is also the wise proverb on bravery and caution about life typical example is "The chicken says, "Fear is life". The functional moral teaching in this wise saying is that there is time to show bravery and time to show 'fear and cautious retreat. You need to be wise in taking decisions that may affect your life.

How much effects these traditional approaches through these maxims or proverbs have on the training and development of emotional intelligence among Ghanaians depends on the type of supervision from the adults in society. This was captured by Nukunya (1969), when he laments that many parents in the Anlo, Ewe area were absent most of the time due to pressure for work such as fishing, trading and paid job. Assimeng (2007) also notes that the nature of social structure in Ghana even though expected to be communal, due to changing trends many of such families are becoming individualistic. In this case, supervision which hitherto was the role of all adults in community continues to decline and this can affect how the young ones grow and imbibe some of these traits.

Even though there are several maxims which promote virtues of individual responsibility, communalism, morality and hard work among Ghanaians there are others that could be misinterpreted negatively and consequently affect students in that direction (Assimeng, 2007). For instance popular saying such as 'a man has come to contribute but not to do all'. Many people hold the view on this to mean you must not over exert your energy in whatever you are doing especially when it comes to the business of the state. Others such as if you cannot beat them join them tacitly supports and condone wrong doing so instead of exposing the wrong doers you rather join them for acceptance. Another popular strong belief held onto by many in our society is the fact that they equate long service to competence and productivity. The common saying that ' $I$ have been here for long and that this is how we do things' so if they have been doing things the wrong way, it becomes difficult for innovation and any attempt to change the status quo is perceived as rebellion among the new members. Finally there is one very 
important saying that is primarily on orientation about time. A lot of Ghanaians are flexible with time and may approximate time for their functions instead of denoting exact time for their programmes. "This is Ghanaian time syndrome'. This usually happens when they are late for occasions and want to give excuses for their lateness. This belief has made some Ghanaians not to abide exactly by time which is one of the most unfortunate practices since they are passed on to the younger ones in society to the detriment of development because 'time they say is money'.

Based on the review of literature and cultural background of Ghana, a simple model is proposed to explain how emotional intelligence affects the learning process. This model is developed based on Smith, Cowie and Blades, (2014) child development mode

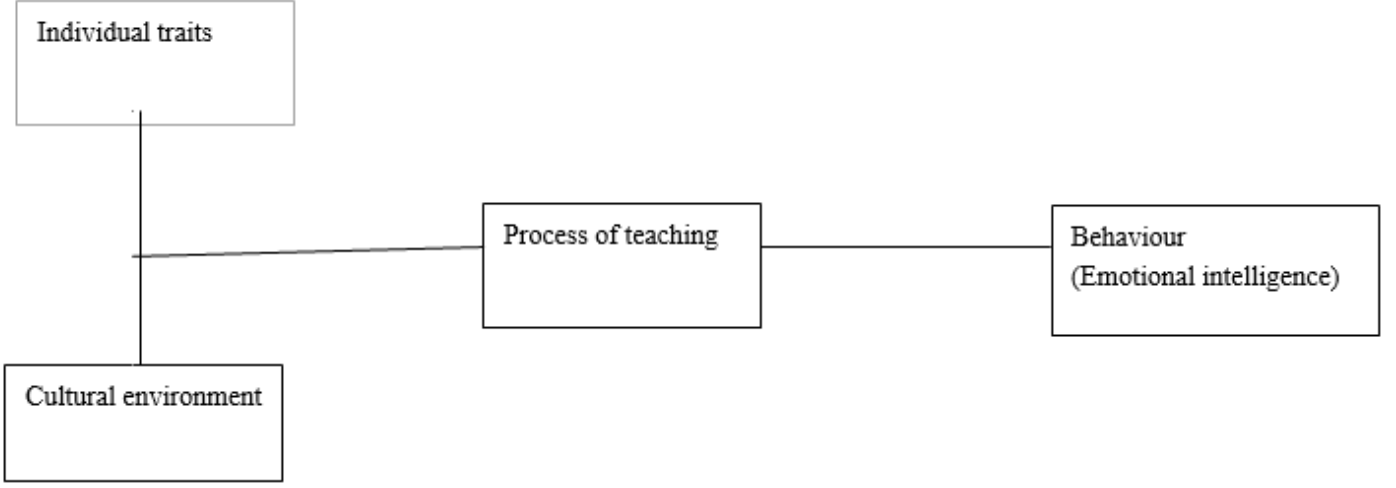

Fig. 1: Environment or culture and influences on emotional intelligence. Adapted from Smith, Cowie and Blades, (2014) child development model.

From the model, it can be observed that even though the individual may be endowed with certain traits, they are very much influenced by the type of culture or environment and the process of teaching and learning eventually determine his final behaviour.

\section{Conclusion}

Culture plays an important role in determining how an individual recognizes, organizes and applies emotional intelligence. The concept is very relevant in regulating people's behavior as well as their ability at performing different tasks. Emotional intelligence can be learnt through both formal educational system and cultural practices. Interesting finding is that both negative and positive aspects of emotional intelligence can be learned through the process of social and cultural transformation. These social skills need to be consciously developed in the students in order to excel on different tasks assigned them and become much more independent minded with entrepreneurial ability.

\section{References}

Appiah, K (1992). In my father's house: Africa in the philosophy of culture. Oxford: Oxford University Press. Assimeng, M. (2007). Social structure of Ghana. ( $2^{\text {nd }}$ ed.). Accra. Ghana Publishing Corporation.

Baxter, J. (1998). Culture and women's mental health: international perspectives and issues for Aotearoa/ New Zealand. In Romans, S.E. (Ed) Folding back the shadows (pp. 63-86) Dunedin, New Zealand: University of Otago Press

Caren, D. P. \& Diehl, C. (2006). Emotional intelligence in diverse population: Theory to intervention. Paper presented at the Association for Applied Sport Psychology conference. Miami, Florida. September, 2006.

Chechi, V.K. (2012). Emotional intelligence and teaching. International journal of Research in Economics and Social Sciences. (2), Issue 2, 234-246.

Damasio, A. (1994). Descarte's error: emotion, reason and human brain, New York Avon Books.

Gardner, J. K., \& Qualter, P. (2010). "Concurrent and incremental validity of three trait emotional intelligence measures". Australian Journal of Psychology 62: 5-12.

Goleman, D. (1995). Emotional intelligence: Why it can matter more than IQ. London: Bloomsbury.

Goleman, D. (1998). Working with emotional intelligence. New York: Bantam Books.

Gyekye, K. (2003). African cultural values: An introduction (5 ${ }^{\text {th }}$ eds..). Accra: Sankofa, Publishing Company.

Idang, G.E. (2015). African culture and values Phronimon 16 (2) 97-111. ISSN 2413-3086.

Illangovan, A., Scroggins, W.A., \& Rozell, J.E. (2007). "Managerial perspectives on emotional intelligence: Differences between India and the United States: The development of research propositions," International Journal of Management, (24) 3, 541-548.

Jassawalla, A, Truglia, C, \& Garvey J. (2004). "Cross-cultural conflict and expatriate manager adjustment," Management Decision, (42):7, 837-849.

Jordan D. (1996). Social skilling through cooperative learning; a complementary approach to behaviour 
management. Master of Educational studies thesis, University of Tasmania.

Le Doux. J. (1996). Emotional brain: The mysterious underpinnings of emotional life. New York: Simon and Schuster.

Leung, A. S.M. (2005). "Emotional intelligence or emotional blackmail: A Study of a Chinese professional-service firm," International Journal of Cross Cultural Management, (5). 2, 181-196.

Mac Mullin C. (1994). The importance of social skills. Paper presented at Rokeby Police Academy, Tasmania

Madhar, M. (2010). Emotional intelligence of teachers and effective class room management. Retrieved June 28, 2020 from http://papers.ssrn.com/sol3/papers.cfm?abstract_id=16661

Mayer, J.D., Salovey, P., \& Caruso, D.R. (2004). Emotional intelligence: Theory, findings, and implications. Psychological Inquiry, 15, 197-215.

Mayer, J. D., Salovey, P., Caruso, D. R., \& Sitaremos, G. (2003). Measuring emotional intelligence with the MSCEIT V2.0. Emotion, 3, 97-105.

Nukunya, G.K. (1969). Kinship and marriage among the Anlo, Ewe. London. Bloomsbury Publishing.

O’ Neil J (1996). Emotional intelligence: a conversation with Daniel Goleman; Educational Leadership. 53, 9, 611.

Petrides, K.V., Furnham, A. (2001). "Trait emotional intelligence: Psychometric investigation with reference to established trait taxonomies". European Journal of Personality. 15 (6): 425-448.

Ross, D (1998). )."Managerial perspectives on emotional intelligence Differences between India and the United States: The Development of Research Propositions," International Journal of Management, Volume 24:3, 541-548.

Seligman, M.E.P, (2002). Authentic Happiness. New York: Free Press

Shipper, F, Kincaid, J. Rotondo, D.M, Richard, C. \& Hoffman I V (2003). "A cross-cultural exploratory study of the linkage between emotional intelligence and managerial effectiveness," International Journal of Organizational Analysis, (11):3, 171- 191

Smith, L., Ciarrochi, J., \& Heaven, P. C. L., (2014). The stability and change of trait emotional intelligence, conflict communication patterns, and relationship satisfaction: A one-year longitudinal study. Personality and Individual Differences, 45, 738-743..

Umoh, J.0. (2005). Elements of Sociology of Religion. Ikot Ekpene: Iwoh Publishers.

Wiredu, K. (1996) Cultural universals and particulars. Bloomington: Indiana University Press.

Zadel, A. (2008). "Do emotionally intelligent leaders have more satisfied employees?" International Journal of Management and Enterprise Development, (5):5, 590-608. 